Article

\title{
Design, Synthesis and Characterization of a New Series of Fluorescent Metabotropic Glutamate Receptor Type 5 Negative Allosteric Modulators
}

\author{
Víctor Fernández-Dueñas ${ }^{1,2, *,+} \oplus$, Mingcheng Qian ${ }^{3,4,+}{ }^{\dagger}$ Josep Argerich ${ }^{1,2}{ }^{\oplus}$, Carolina Amaral ${ }^{1,2}$, \\ Martijn D.P. Risseeuw ${ }^{3}$, Serge Van Calenbergh ${ }^{3, * *(1)}$ and Francisco Ciruela $1,2, *$ (D) \\ 1 Unitat de Farmacologia, Departament de Patologia i Terapèutica Experimental, Facultat de Medicina i \\ Ciències de la Salut, IDIBELL, Universitat de Barcelona, 08907 L'Hospitalet de Llobregat, Spain; \\ jargerich95@gmail.com (J.A.); ccarolinaamaral@gmail.com (C.A.) \\ 2 Institut de Neurociències, Universitat de Barcelona, 08035 Barcelona, Spain \\ 3 Laboratory for Medicinal Chemistry (FFW), Ghent University, Ottergemsesteenweg 460, B-9000 Ghent, \\ Belgium; mqian2019@cczu.edu.cn (M.Q.); Martijn.Risseeuw@UGent.be (M.D.P.R.) \\ 4 Laboratory of Toxicology, Ghent University, Ottergemsesteenweg 460, B-9000 Ghent, Belgium \\ * Correspondence: vfernandez@ub.edu (V.F.-D.); serge.vancalenbergh@ugent.be (S.V.C.); \\ fciruela@ub.edu (F.C.) \\ + These authors contributed equally to the work.
}

Academic Editor: Sławomir Filipek

Received: 28 February 2020; Accepted: 21 March 2020; Published: 27 March 2020

check for updates

\begin{abstract}
In recent years, new drug discovery approaches based on novel pharmacological concepts have emerged. Allosteric modulators, for example, target receptors at sites other than the orthosteric binding sites and can modulate agonist-mediated activation. Interestingly, allosteric regulation may allow a fine-tuned regulation of unbalanced neurotransmitter' systems, thus providing safe and effective treatments for a number of central nervous system diseases. The metabotropic glutamate type 5 receptor $\left(\mathrm{mGlu}_{5} \mathrm{R}\right)$ has been shown to possess a druggable allosteric binding domain. Accordingly, novel allosteric ligands are being explored in order to finely regulate glutamate neurotransmission, especially in the brain. However, before testing the activity of these new ligands in the clinic or even in animal disease models, it is common to characterize their ability to bind $\mathrm{mGlu}_{5}$ Rs in vitro. Here, we have developed a new series of fluorescent ligands that, when used in a new NanoBRET-based binding assay, will facilitate screening for novel $\mathrm{mGlu}_{5} \mathrm{R}$ allosteric modulators.
\end{abstract}

Keywords: $\mathrm{mGlu}_{5} \mathrm{R}$; fluorescent ligands; allosterism; nanoBRET

\section{Introduction}

G protein-coupled receptors (GPCRs) are a superfamily of transmembrane receptors that detect and transmit a large array of extracellular signals (i.e., sensory stimuli, hormones, neurotransmitters), which allow regulating many different physiological functions (i.e., vision, blood pressure, central nervous system activity) [1]. Accordingly, these kinds of receptors represent the main target ( 35\%) of clinically used drugs [2]. Most GPCR-targeting drugs consist of ligands, either agonists or antagonists, which bind to the endogenous ligand (orthosteric) binding site. However, in recent years, an emerging alternative approach to develop novel drugs consists of searching for allosteric ligands, which: (i) bind to sites topographically distinct from the orthosteric one, and (ii) typically, do not possess intrinsic activity, but only modulate the endogenous ligand-mediated function [3]. There exist two kinds of allosteric modulators, positive and negative allosteric modulators (PAM and NAM, respectively) [3]. Both PAM and NAM may offer a number of advantages over typical orthosteric ligands. For instance, these drugs have the potential for higher receptor subtype selectivity, since the allosteric binding 
pockets present higher sequence diversity compared to their orthosteric counterparts, which are more conserved and are thus likely to trigger off-target effects [4,5]. However, the main strength of allosteric modulators consists of their inability of activating receptors by their own. The activity of these kinds of drugs depends on endogenous ligands-mediated signaling, thus they may finely modulate receptors instead of fully activating/blocking them [5]. Interestingly, the fine-tuning regulation of receptors may be especially relevant in pathologies in which neurotransmission systems are unbalanced. This is the case, for instance, for benzodiazepines, which provide a safe (with a high therapeutic index) and effective treatment for anxiety, acting as PAMs for the $\mathrm{GABA}_{\mathrm{A}}$ receptor [6].

Based on the previous notions, in recent years, a number of receptor subtype-selective allosteric ligands have been developed for different neurotransmitters' receptors [7-10], such as the metabotropic glutamate receptors (mGluR), which are involved in numerous central nervous system pathologies (i.e., schizophrenia, pain, depression, Parkinson's disease) [11-13]. Glutamate is the major excitatory neurotransmitter within the central nervous system and exerts its effects by interacting with two main types of receptors (ionotropic and metabotropic) [14,15]. There are eight subtypes of metabotropic receptors, which are divided into three groups (I, II, III) based on their homology, G-protein coupling and pharmacological profile $[14,15]$. Group $I$, comprising $m G l u_{1} R$ and $m G u_{5} R$, are coupled to $G_{q} / G_{11}$ proteins, and upon stimulation lead to phospholipase $\mathrm{C}$ activation, $\mathrm{IP}_{3}$ accumulation, and $\mathrm{Ca}^{2+}$ release from intracellular stores [15]. These receptors are characterized by a large N-terminal domain, termed as the venus-flytrap domain, which contains the endogenous ligand-binding site; while the allosteric binding site(s) is located at the transmembrane domain [5]. Interestingly, to screen for novel $\mathrm{mGlu}_{1} \mathrm{R}$ and $\mathrm{mGlu}_{5} \mathrm{R}$ PAMs or NAMs, radioligands and positron emission tomography (PET) ligands have been developed [5]. These kinds of ligands allow performing cell-based assays, in which apart from assessing orthosteric agonist modulation, it is possible to perform binding competition assays to assess affinity for the allosteric binding site. However, both PET and radioligand binding are expensive, time-consuming and/or hazardous techniques, thus implementing fluorescence-based tools could be desirable. The main drawback of using fluorescent $\mathrm{mGlu}_{5} \mathrm{R}$ allosteric ligands is related to their high lipophilic nature, which may cause adsorption to cell surfaces [15]. To circumvent this drawback, resonance energy transfer (RET) techniques can be implemented [16,17].

Here, we have developed a new approach to screen for $\mathrm{mGlu}_{5} \mathrm{R}$ allosteric ligands, based on the engagement of a BRET process between $\mathrm{mGlu}_{5 \mathrm{~b}} \mathrm{R}$ labelled with a nanolucifecrase (i.e., NanoLuc) and selective fluorescent allosteric ligands. Accordingly, we have designed and synthetized a new series of fluorescent mGlu $_{5}$ R NAMs, which may be useful to develop a high-throughput screening for novel $\mathrm{mGlu}_{5} \mathrm{R}$ allosteric ligands.

\section{Results}

\subsection{Design and Synthesis of the Fluorescent Ligands}

Boron dipyrromethene (BODIPY) is a fluorescent dye with diverse properties, such as photochemical stability, high molar absorptivity, high fluorescence quantum yield, and the fact that its fluorescence property can be altered by varying the substitution pattern on the core and the flanking pyrroles. Alkyne functionalized BODIPY dyes can be used to fluorescently label an azido functionalized ligand in a chemo selective manner employing the copper-catalyzed azide-alkyne cycloaddition (CuAAC) reaction [18]. Here, we exploited alkyne functionalized BODIPY (573/607) to construct a small set of fluorescent $\mathrm{mGlu}_{5} \mathrm{R}$ ligands based on MTEP (Figure 1).

The $\mathrm{mGlu}_{5} \mathrm{R}$ carboxylate derivatives were condensed with different spacers containing both an amine and azide terminus in the presence of the coupling agent EDC and triethylamine to yield six intermediate azides as described previously [19]. The synthesis of the desired fluorescent ligands was accomplished by reacting each of these azides with an alkyne-modified BODIPY red dye through $\mathrm{CuAAC}$. This afforded a concise series of six $\mathrm{mGlu}_{5} \mathrm{R}$ fluorescent ligands $\mathbf{4 a - f}$ (Figure 2). 


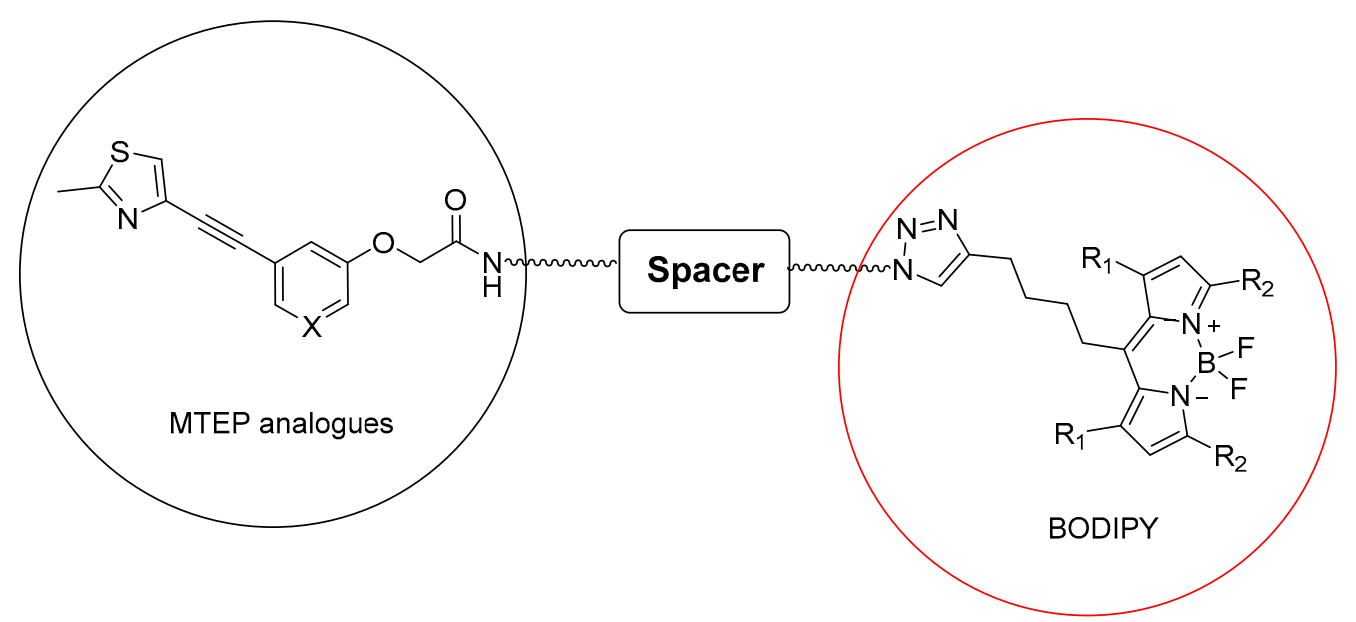

Figure 1. Schematic design of fluorescent $\mathrm{mGlu}_{5} \mathrm{R}$ ligands based on BODIPY.<smiles>[X]c1cc(C#Cc2csc(C)n2)cc(OCC(=O)NCCOCCOCCn2cc(CCCCC3=C4C=CC(c5ccc(OC)cc5)=[N+]4B(F)n4c3ccc4-c3ccc(OC)cc3)nn2)c1</smiles>

4a: $X=N, n=4$

4b: $\mathrm{X}=\mathrm{CH}, \mathrm{n}=2$<smiles>[X]c1cc(C#Cc2csc(C)n2)cc(OCC(=O)NCCCCCN(C)C(C)CCCCCCCCCCc2cn(C)nn2)c1</smiles>

4c: $\mathrm{X}=\mathrm{CH}, \mathrm{n}=5$

4d: $X=\mathrm{N}, \mathrm{n}=5$

4e: $X=N, n=3$

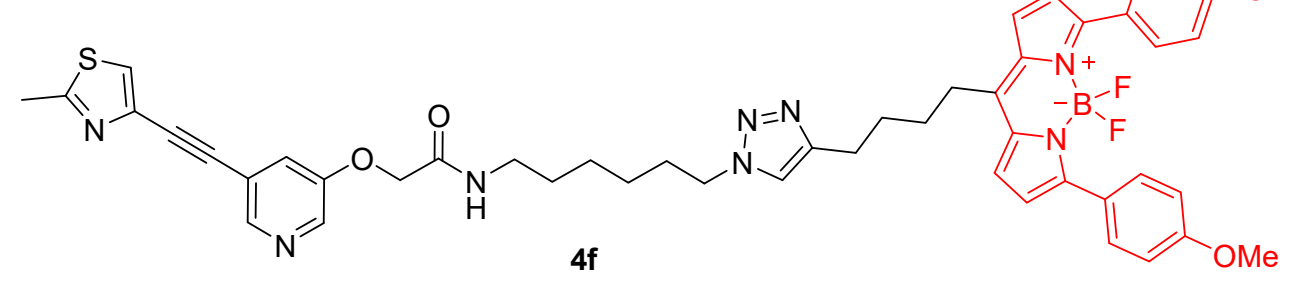

Figure 2. Structural design of the $\mathrm{mGlu}_{5} \mathrm{R}$ fluorescent ligands. Chemical representation of the six fluorescent NAMs (4a-f) in which a boron dipyrromethene (BODIPY; shown in red) fluorophore is fused with MTEP analogues by different spacers (shown in black).

The excitation and emission spectra of the fluorescent $\mathrm{mGlu}_{5} \mathrm{R}$ ligands was determined. All ligands exhibited similar excitation and emission wavelengths with comparable spectral separation $(\sim 40 \mathrm{~nm})$ between them (Figure 3a). Next, we assessed the fluorescence intensity by exciting ligands at $573 \mathrm{~nm}$ (the theoretical peak of excitation of BODIPY) and at $490 \mathrm{~nm}$ (the emission wavelength of NanoLuc). We used the same concentration of each ligand $(10 \mu \mathrm{M})$ and read fluorescence intensity at $607 \mathrm{~nm}$ (the theoretical peak of emission of BODIPY) and $610 \mathrm{~nm}$ (the wavelength to be read after the BRET process between NanoLuc and the fluorescent ligands), respectively. As shown in Figure 3b, ligand 4a exhibited a significantly higher fluorescence emission intensity compared to the other ligands. Notably, the high 
fluorescence emission intensity observed at $610 \mathrm{~nm}$ upon $490 \mathrm{~nm}$ excitation supported the possibility of using $4 \mathbf{a}$ in the subsequent nanoBRET binding assay. In addition, we also selected $4 \mathbf{e}$ to be used in further experiments, based on the fact that it exhibited the second highest fluorescence emission intensity at both wavelengths (Figure 3b).

(a)
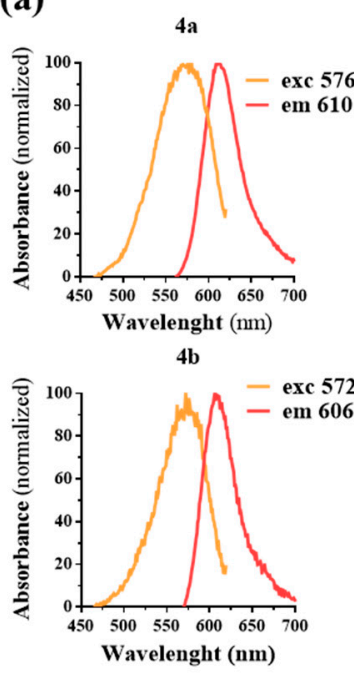

$4 \mathrm{c}$

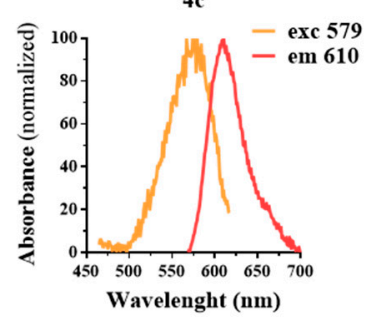

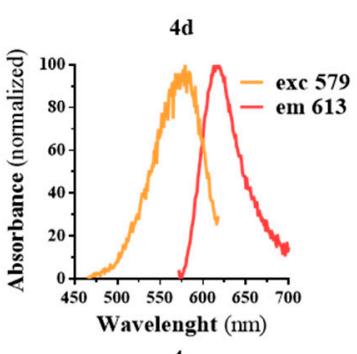

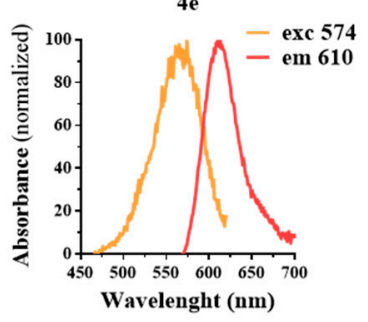

4f

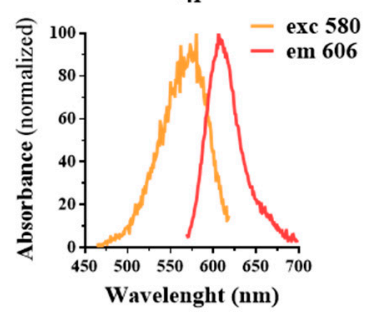

(b)
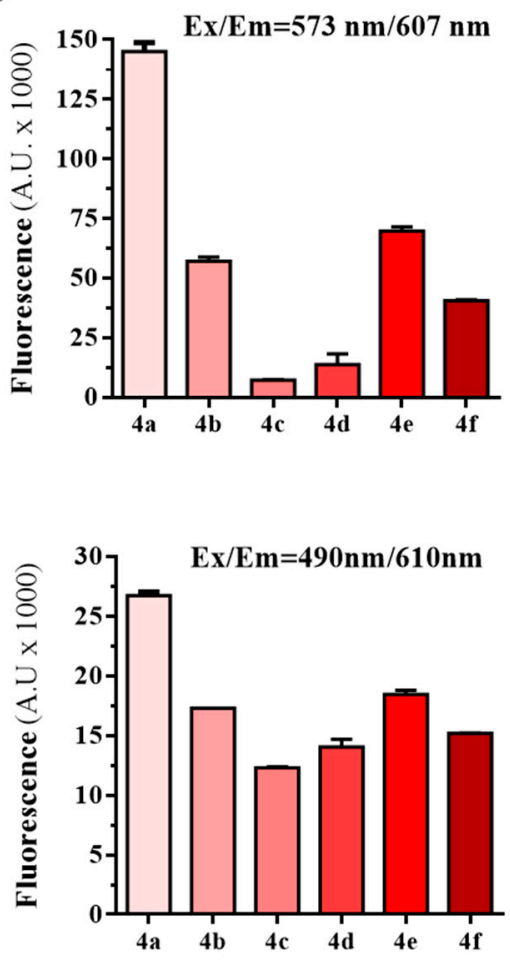

Figure 3. Characterization of the fluorescent properties of conjugates $4 \mathbf{a}-\mathbf{f}$. (a) Excitation and emission spectra of the $\mathrm{mGlu}_{5} \mathrm{R}$ fluorescent ligands $\mathbf{4 a - f}$. The excitation/emission wavelength peak for each compound is shown in nanometers. (b) Fluorescence emission (arbitrary units, A.U.) at $607 \mathrm{~nm}$ or $610 \mathrm{~nm}$ is shown after exciting (573 nm or $490 \mathrm{~nm}$, respectively) the six BODIPY-conjugates $(10 \mu \mathrm{M}$ solution in $0.05 \%$ DMSO of $4 \mathrm{a}$ to $4 \mathrm{f}$ depicted as light to dark red columns). This value is related to the quantum yield of each fluorophore.

\subsection{Characterization of the NanoBRET Binding Assay}

To set up the nanoBRET binding assay, we first validated the cloning of the $\mathrm{mGlu}_{5 \mathrm{~b}} \mathrm{R}^{\mathrm{NL}}$ construct. Using immunoblot analysis, $\mathrm{mGlu}_{5 b} \mathrm{R}^{\mathrm{NL}}$ expression was ascertained by the presence of a protein band of molecular weight $\sim 150 \mathrm{kDa}$, corresponding to the sum of $\mathrm{mGlu}_{5 \mathrm{~b}} \mathrm{R}(\sim 130 \mathrm{kDa})$ and NanoLuc ( $19 \mathrm{kDa}$ ) proteins (Figure 4a). Moreover, we ascertained the luminescence of cells expressing the $\mathrm{mGlu}_{5 \mathrm{~b}} \mathrm{R}^{\mathrm{NL}}$, by incubating these with the enzyme's substrate (coelenterazine $400 \mathrm{a}, 1 \mu \mathrm{M}$ ). While in mock-transfected cells no signal was observed, a robust luminescent signal was obtained in $\mathrm{mGlu}_{5 \mathrm{~b}} \mathrm{R}^{\mathrm{NL}}$ upon incubation for $5 \mathrm{~min}$ with coelenterazine 400a (Figure $4 \mathrm{~b}$ ). Next, we evaluated whether the fluorescent ligands could bind and activate $\mathrm{mGlu}_{5 b} \mathrm{R}$, a condition sine qua non for using them in a nanoBRET binding assay. First, we imaged $\mathrm{mGlu}_{5 b} \mathrm{R}^{\mathrm{SNAP}}$-expressing cells (Figure $4 \mathrm{c}$ ) superfused with the fluorescent ligand 4a. Interestingly, 4a nicely decorated the cell surface, but was also present inside the cell after $5 \mathrm{~min}$ of incubation (Figure $4 \mathrm{~d}$ ). The fact that the ligand penetrated into the cell, either by diffusion or endocytosis, supported the need for developing the nanoBRET binding assay instead of determining fluorescence intensity.

Next, we tested whether the fluorescent ligands maintained their ability to allosterically modulate agonist-mediated $m G l u_{5} R$ signalling. Accordingly, cells were transfected with the $\mathrm{mGlu}_{5 \mathrm{~b}} \mathrm{R}^{\mathrm{SNAP}}$ 
construct and a NFAT-luciferase reporter plasmid (pGL4-NFAT-RE/luc2p) to indirectly determine intracellular $\mathrm{Ca}^{2+}$ accumulation (Figure 5a). In these cells, activation of $\mathrm{mGlu}_{5 \mathrm{~b}} \mathrm{R}$ via the application of the agonist quisqualic acid $(100 \mu \mathrm{M})$ increased intracellular $\mathrm{Ca}^{2+}$, which enhanced NFAT-sensitive expression of the luciferase reporter (Figure 5b). Conversely, intracellular $\mathrm{Ca}^{2+}$ accumulation was blocked when cells were co-incubated with quisqualic acid (100 $\mu \mathrm{M})$ and either the prototypic $\mathrm{mGlu}_{5} \mathrm{R}$ NAM MTEP or ligands $4 \mathbf{a}$ and $4 \mathbf{e}$ (Figure $5 \mathrm{~b}$ ). It can thus be concluded that the fluorescent ligands tested retained the ability to bind and allosterically modulate $\mathrm{mGlu}_{5} \mathrm{R}$ activity.

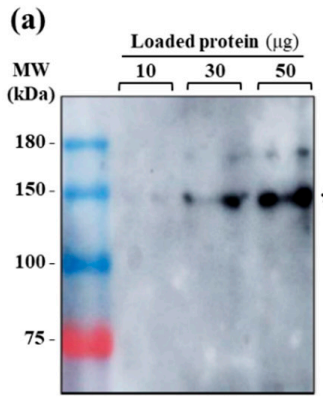

(b)

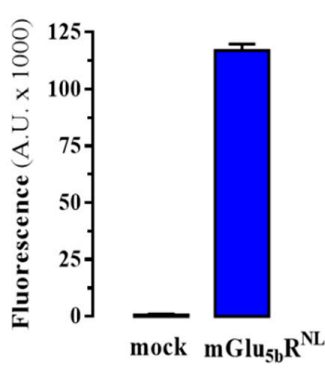

(c)

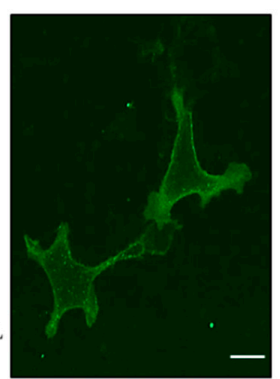

(d)

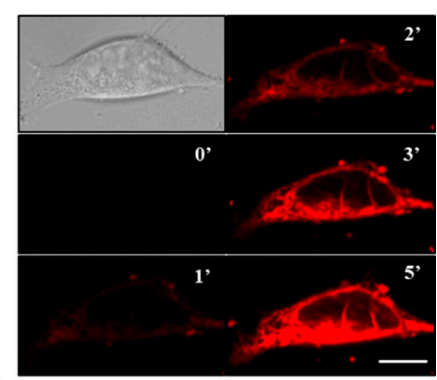

Figure 4. Evaluation of the $\mathrm{mGlu}_{5 \mathrm{~b}} \mathrm{R}$ constructs and ligand $4 \mathbf{a}$ in living cells. (a) Immunoblot detection of $\mathrm{mGlu}_{5 \mathrm{~b}} \mathrm{R}^{\mathrm{NL}}$. Increasing amounts of membrane extracts $(10 \mu \mathrm{g}, 30 \mu \mathrm{g}$ and $50 \mu \mathrm{g}$ of protein) from HEK293T cells transiently transfected with $\mathrm{mGlu}_{5 \mathrm{~b}} \mathrm{R}^{\mathrm{NL}}$ were analyzed by immunoblotting using a rabbit anti-mGlu ${ }_{5} \mathrm{R}$ antibody $(1 \mu \mathrm{g} / \mathrm{mL})$. Asterisk indicates the expected molecular weight $(\sim 150 \mathrm{kDa})$ of $m_{G l u_{5 b}} R^{N L}$. (b) Luminescence detection of $m_{G l u} R^{N L}$. HEK293T cells transiently transfected with $\mathrm{mGlu}_{5 b} \mathrm{R}^{\mathrm{NL}}$ were incubated with coelenterazine 400a for $5 \mathrm{~min}$ and luminescence recorded using a CLARIOStar plate reader. (c) The expression of $\mathrm{mGlu}_{5 b} \mathrm{R}^{\mathrm{SNAP}}$ was determined by assessing the fluorescence obtained after staining cells with the SNAP-Surface 647 substrate. (d) Ligand (4a) association to and diffusion in $\mathrm{mGlu}_{5 \mathrm{~b}} \mathrm{R}^{\mathrm{SNAP}}$ expressing cells as assessed by laser scanning confocal microscopy. The increase of the fluorescent signal was followed during $5 \mathrm{~min}$. Scale bar: $100 \mu \mathrm{m}$.
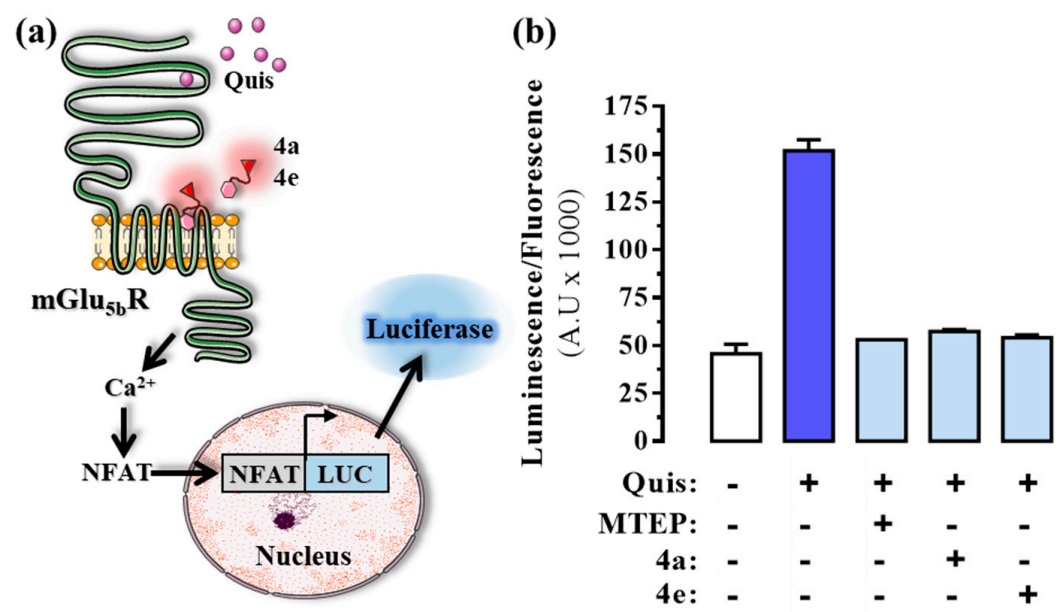

Figure 5. Effect of the fluorescent mGlu $_{5} \mathrm{R}$ NAMs on intracellular calcium levels in HEK293T cells. (a) Schematic representation of the NFAT-luciferase reporter assay in which intracellular calcium levels were determined in the presence of quisqualic acid together with the fluorescent $\mathrm{mGlu}_{5} \mathrm{R}$ ligands $4 \mathbf{a}$ and 4e. (b) HEK293T cells transfected with mGlu $_{5 b} R^{\text {SNAP }}$ were first labelled with a non-permeable SNAP substrate (SNAP-Surface 647). Next, cells were incubated with $100 \mu \mathrm{M}$ of quisqualic acid (Quis) alone or in combination with $5 \mu \mathrm{M}$ of MTEP, $4 \mathbf{a}$ or $4 \mathbf{e}$ for $6 \mathrm{~h}$ at $37^{\circ} \mathrm{C}$. The ratio between the luciferase activity $(535 \mathrm{~nm})$ and the fluorescence intensity of the receptor $(647 \mathrm{~nm})$ was calculated to normalize the signal by the number of receptor-expressing cells. Data are the mean \pm SEM of three independent experiments performed in triplicate. ${ }^{* *} p<0.01$, one-way ANOVA followed by Dunnett's post-hoc test. Figure designed using image templates from [20]. 


\subsection{NanoBRET Binding Assay}

Finally, we performed the nanoBRET binding assay (Figure 6a) by transfecting cells with the $\mathrm{mGlu}_{5 b} \mathrm{R}^{\mathrm{NL}}$ construct and challenging increasing concentrations of the fluorescent ligands, in the presence/absence of the non-labeled MTEP. Interestingly, a binding saturation hyperbola was obtained for both $4 \mathrm{a}\left(\mathrm{K}_{\mathrm{D}}=0.84 \pm 0.74 \mu \mathrm{M}\right.$ and $\left.\mathrm{B}_{\max }=37.3 \pm 11.4 \%\right)$ and $4 \mathrm{e}\left(\mathrm{K}_{\mathrm{D}}=1.4 \pm 1.2 \mu \mathrm{M}\right.$ and $\left.\mathrm{B}_{\max }=54.3 \pm 18.5 \%\right)$, while in the presence of a saturating concentration of MTEP $(10 \mu \mathrm{M})$ the binding was displaced (Figure 6b). Hence, our results show that, despite the high lipophilic nature of the fluorescent ligands, it is possible to engage a BRET process, thus supporting that this nanoBRET binding assay is a robust and reliable way to assess $\mathrm{mGlu}_{5} \mathrm{R}$ allosteric ligand binding.

(a)

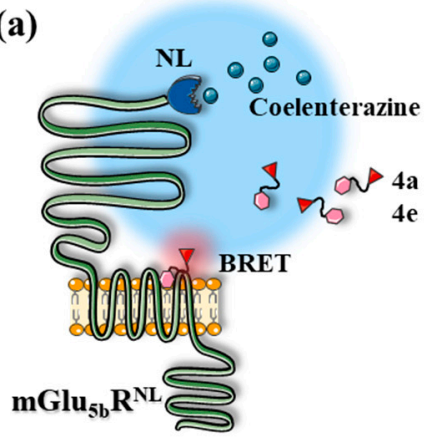

(b)

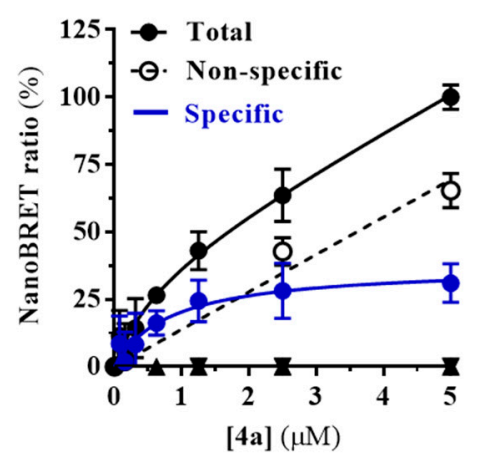

(c)

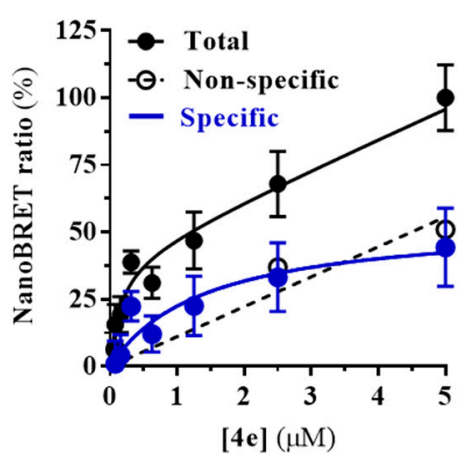

Figure 6. Determination of the binding affinity of $4 \mathbf{a}$ and $4 \mathbf{e}$ at $\mathrm{mGlu}_{5 \mathrm{~b}} \mathrm{R}$ using the nanoBRET assay. (a) Illustrative representation of the nanoBRET assay in which a nanoluciferase linked to the N-terminal part of the mGlu $\mathrm{bb}_{\mathrm{b}} \mathrm{R}$ (donor) emits light at $490-10 \mathrm{~nm}$ in presence of coelenterazine. The light excites the BODIPY attached to the ligand (acceptor), which subsequently emits fluorescence at $650-80 \mathrm{~nm}$. $(\mathbf{b}, \mathbf{c})$ NanoBRET saturation binding curves obtained by challenging $\mathrm{mGlu}_{5 \mathrm{~b}} \mathrm{R}^{\mathrm{NL}}$ expressing HEK293T cells with increasing concentrations of $\mathbf{4 a}(\mathbf{b})$ or $\mathbf{4 e}(\mathbf{c})$ in the absence (black circles) or presence (white circles) of $10 \mu \mathrm{M}$ MTEP for $1 \mathrm{~h}$ at $37^{\circ} \mathrm{C}$. The specific binding curve (blue circles), the $K_{D}$ and the $B_{\max }$ is shown for each ligand. The represented data are mean \pm SEM of three independent experiments each performed in triplicate. Figure designed using image templates from [20].

\section{Discussion}

In recent years, different $\mathrm{mGlu}_{5} \mathrm{R}$ allosteric drugs have shown efficacy in preclinical animal models of disease (i.e., anxiety, depression, drug abuse) [13]. Indeed, a number of clinical trials have been engaged, but, to our knowledge, most studies have failed to translate preclinical findings into clinics (for review see [21,22]). However, it is important to note that in most cases (i.e., basimglurant in depression), the inconclusive data obtained in clinical trials may be explained by some of the intrinsic issues of these kinds of trials, such as the placebo effect or limitations related to the treatment duration or to the selection of a single dose [22]. Accordingly, in the next years, designing better clinical trials is a major challenge to develop improved $\mathrm{mGlu}_{5} \mathrm{R}$ allosteric drugs. As there remains a high interest in developing these kinds of drugs, novel tools to rapidly characterize allosteric ligands are clearly awaited. Here, we have designed, synthesized, and characterized a novel series of fluorescent $\mathrm{mGlu}_{5} \mathrm{R}$ NAMs, which can be used in a nanoBRET assay to robustly and reliably assess mGlu $\mathrm{R}_{5}$ allosteric ligand binding. This assay based on RET overcomes some of the drawbacks of other typical techniques, such as PET or radioligand binding. For instance, PET ligands can be extremely useful to visualize disruptions in glutamate transmission or to select the dose to be used in clinical trials, but they are expensive to perform ligand binding competition assays. Similarly, radioligand binding assays may provide robust data concerning pharmacological constants, but they are also expensive, harmful, time-consuming and difficult to miniaturize [16,23]. Regarding RET-based assays, a number of approaches have been implemented to study orthosteric ligand-receptor binding. For instance, a FRET-based assay (i.e., 
Tag-lite binding assay) was successfully and reproducibly applied to test novel ligands for different GPCRs, demonstrating its suitability for high-throughput screening [23]. Similarly, a new BRET-based assay was recently developed using GPCRs tagged with a NanoLuc protein to engage a RET process with fluorescent ligands $[17,24]$. Interestingly, this assay was truly homogenous (without any washing step), since it did not require conjugating a fluorophore to the GPCR (as in the Tag-lite assay), and was extremely sensitive, due to the brightness of the NanoLuc luciferase $[17,24]$. In the present work, we took advantage of this observation to investigate allosteric ligand binding. Of note, both the non-washing conditions and high sensitivity of the nanoBRET binding approach allowed to perform this kind of assay even with highly lipophilic fluorescent $\mathrm{mGlu}_{5} \mathrm{R}$ allosteric ligands. Despite the fact that these molecules were rapidly adsorbed and penetrated the plasma membrane, thus accumulating into the cell, it was possible to detect a specific signal dependent on $\mathrm{mGlu}_{5} \mathrm{R}$ ligand binding. In addition, it is noteworthy that the fluorescent ligands maintained the ability to interact and modulate agonist-mediated responses, thus it could be discarded that the BODIPY dye affects ligand binding. On the other hand, it is important to note that we used BODIPY derivatives with excitation/emission peaks at $573 / 607 \mathrm{~nm}$. The reason for this is that NanoLuc exhibits a high emission upon coelenterazine incubation, and this signal overlaps and masks specific BRET signals when using dyes with lower excitation/emission wavelengths (data not shown). Altogether, our nanoBRET binding assay permitted to robustly assess $\mathrm{mGlu}_{5} \mathrm{R}$ allosteric ligand binding and may be viewed as a useful tool to develop novel $\mathrm{mGlu}_{5} \mathrm{R}$ allosteric ligands.

\section{Materials and Methods}

\subsection{Chemistry}

All reactions described were performed under an $\mathrm{N}_{2}$ atmosphere and at ambient temperature, unless stated otherwise. All reagents and solvents were purchased from Sigma-Aldrich (Diegem, Belgium), Fisher Scientific (Merelbeke, Belgium), TCI Europe (Zwijndrecht, Belgium) or Apollo Scientific (Bredbury, Stockport, UK), and used as received. NMR solvents were acquired from Eurisotop (Saint-Aubin, France). ESI-HRMS spectra were measured with a Waters LCT Premier XE Mass spectrometer calibrated using leu-enkephalin as an external standard. LC-MS analyses were carried out on a Waters AutoPurification System equipped with PDA and ESI-MS detection and using a Waters CORTECS C18 Column $(4.6 \times 100 \mathrm{~mm}, 2.7 \mu \mathrm{m})$ and a water/acetonitrile/formic acid linear gradient system at a flow rate of $1.44 \mathrm{~mL} \mathrm{~min}^{-1}$.

General procedure 1: Copper mediated azide-alkyne cycloaddition. To a solution of the azido-linker modifies MTEP analogues [19] (1.0 eq.) in dimethylformamide (0.1 M) was added the alkyne-modified BODIPY-red (1.5 eq.), sodium ascorbate (1.0 eq., $0.5 \mathrm{M}), \mathrm{CuSO}_{4}(0.2$ eq., 0.05 $\mathrm{M})$, triethylamine (3.0 eq.) and a catalytic amount of tris[(1-benzyl-1,2,3-triazol-4-yl)methyl]amine. The reaction mixture was stirred overnight at room temperature in the dark under an argon atmosphere. The solvent was evaporated under reduced pressure and the residue was partioned between water and $\mathrm{CH}_{2} \mathrm{Cl}_{2}$. The organic fraction was washed with brine and dried over $\mathrm{Na}_{2} \mathrm{SO}_{4}$. The crude compound was purified by silica gel chromatography $\left(\mathrm{NH}_{4} \mathrm{OH} / \mathrm{MeOH} / \mathrm{CH}_{2} \mathrm{Cl}_{2}, 1: 5: 94 \mathrm{v} / \mathrm{v} / \mathrm{v}\right)$ to give the final compounds as blue solids.

N-(17-(4-(4-(5,5-difluoro-3,7-bis(4-methoxyphenyl)-5H-4 $\lambda^{4}, 5 \lambda^{4}$-dipyrrolo [1,2-c:2', $\left.1^{\prime}-f\right][1,3,2]$ diazaborinin10-yl)butyl)-1H-1,2,3-triazol-1-yl)-3,6,9,12,15-pentaoxaheptadecyl)-2-((5-((2-methylthiazol-4-yl)ethynyl)pyridin3-yl)oxy)acetamide (4a)

Blue solid, $48 \%$. LC-HRMS: $t_{\mathrm{R}}=7.99 \mathrm{~min}(10-100 \% \mathrm{MeCN}, 15 \mathrm{~min}$ run), purity $95.4 \%$. HRMS (ESI) $m / z$ : calculated for $\mathrm{C}_{54} \mathrm{H}_{63} \mathrm{BF}_{2} \mathrm{~N}_{8} \mathrm{O}_{9} \mathrm{~S}[\mathrm{M}+2 \mathrm{H}]^{2+}$ 524.2244; found 524.2223. Calculated for $\mathrm{C}_{54} \mathrm{H}_{62} \mathrm{BFN}_{8} \mathrm{O}_{9} \mathrm{~S}[\mathrm{M}-\mathrm{F}+\mathrm{H}]^{2+}$ 514.2219; found 514.2209. 
N-(2-(2-(2-(2-(4-(4-(5,5-difluoro-3,7-bis(4-methoxyphenyl)-5H-4 $\lambda^{4}, 5 \lambda^{4}$-dipyrrolo[1,2-c:2',1'-f][1,3,2]diazaborinin10-yl)butyl)-1H-1,2,3-triazol-1-yl)ethoxy)ethoxy)ethoxy)-ethyl)-2-(3-((2-methylthiazol-4-yl)ethynyl)phenoxy) acetamide (4b)

Blue solid, 52\%. LC-HRMS: $t_{\mathrm{R}}=7.62 \mathrm{~min}(10-100 \% \mathrm{MeCN}, 15 \mathrm{~min}$ run), purity $96.8 \%$. HRMS (ESI) $m / z$ : calculated for $\mathrm{C}_{51} \mathrm{H}_{56} \mathrm{BF}_{2} \mathrm{~N}_{7} \mathrm{O}_{7} \mathrm{~S}[\mathrm{M}+2 \mathrm{H}]^{2+}$ 479.7006; found 479.6974. Calculated for $\mathrm{C}_{51} \mathrm{H}_{55} \mathrm{BF}_{2} \mathrm{~N}_{7} \mathrm{O}_{7} \mathrm{~S}[\mathrm{M}+\mathrm{H}]^{+}$958.3939; found 958.3953 .

N-(5-((12-(4-(4-(5,5-difluoro-3,7-bis(4-methoxyphenyl)-5H-4 $\lambda^{4}, 5 \lambda^{4}$-dipyrrolo[1,2-c:2',1'-f][1,3,2]diazaborinin10-yl)butyl)-1H-1,2,3-triazol-1-yl)dodecyl)(methyl)amino)pentyl)-2-(3-((2-methylthiazol-4-yl)ethynyl)phenoxy) acetamide (4c)

Blue solid, $46 \%$. LC-HRMS: $t_{\mathrm{R}}=9.53 \mathrm{~min}(10-100 \% \mathrm{MeCN}, 15 \mathrm{~min}$ run), purity $85.4 \%$. HRMS (ESI) $m / z$ : calculated for $\mathrm{C}_{61} \mathrm{H}_{77} \mathrm{BF}_{2} \mathrm{~N}_{8} \mathrm{O}_{4} \mathrm{~S}[\mathrm{M}+2 \mathrm{H}]^{2+}$ 533.2919; found 533.2914. Calculated for $\mathrm{C}_{61} \mathrm{H}_{76} \mathrm{BFN}_{8} \mathrm{O}_{4} \mathrm{~S}[\mathrm{M}-\mathrm{F}+\mathrm{H}]^{2+}$ 523.2893; found 523.2885.

N-(5-((12-(4-(4-(5,5-difluoro-3,7-bis(4-methoxyphenyl)-5H-4 $4 \lambda^{4}, 5 \lambda^{4}$-dipyrrolo[1,2-c:2',1'-f][1,3,2]diazaborinin10-yl)butyl)-1H-1,2,3-triazol-1-yl)dodecyl)(methyl)amino)pentyl)-2-((5-((2-methylthiazol-4-yl)ethynyl)pyridin3-yl)oxy)acetamide (4d)

Blue solid, 39\%. LC-HRMS: $t_{\mathrm{R}}=6.86 \mathrm{~min}(10-100 \% \mathrm{MeCN}, 15 \mathrm{~min}$ run), purity $90.8 \%$. HRMS (ESI) $m / z$ : calculated for $\mathrm{C}_{60} \mathrm{H}_{76} \mathrm{BF}_{2} \mathrm{~N}_{9} \mathrm{O}_{4} \mathrm{~S}[\mathrm{M}+2 \mathrm{H}]^{2+}$ 533.7895; found 533.7896. Calculated for $\mathrm{C}_{60} \mathrm{H}_{75} \mathrm{BFN}_{9} \mathrm{O}_{4} \mathrm{~S}[\mathrm{M}-\mathrm{F}+\mathrm{H}]^{2+}$ 523.7870; found 523.7874 .

N-(5-((8-(4-(4-(5,5-difluoro-3,7-bis(4-methoxyphenyl)-5H-4 $\lambda^{4}, 5 \lambda^{4}$-dipyrrolo[1,2-c:2',1'-f][1,3,2]diazaborinin10-yl)butyl)-1H-1,2,3-triazol-1-yl)octyl)(methyl)amino)pentyl)-2-((5-((2-methylthiazol-4-yl)ethynyl)pyridin3-yl)oxy)acetamide (4e)

Blue solid, 37\%. LC-HRMS: $t_{\mathrm{R}}=5.93 \mathrm{~min}(10-100 \% \mathrm{MeCN}, 15 \mathrm{~min}$ run), purity $82.5 \%$. HRMS (ESI) $m / z$ : calculated for $\mathrm{C}_{56} \mathrm{H}_{68} \mathrm{BF}_{2} \mathrm{~N}_{9} \mathrm{O}_{4} \mathrm{~S}[\mathrm{M}+2 \mathrm{H}]^{2+}$ 505.7582; found 505.7570. Calculated for $\mathrm{C}_{56} \mathrm{H}_{67} \mathrm{BFN}_{9} \mathrm{O}_{4} \mathrm{~S}[\mathrm{M}-\mathrm{F}+\mathrm{H}]^{2+}$ 495.7557; found 495.7557.

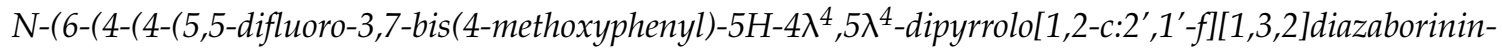
10-yl)butyl)-1H-1,2,3-triazol-1-yl)hexyl)-2-((5-((2-methylthiazol-4-yl)ethynyl)pyridin-

3-yl)oxy)acetamide (4f)

Blue solid, $45 \%$. LC-HRMS: $t_{\mathrm{R}}=7.32 \mathrm{~min}(10-100 \% \mathrm{MeCN}, 15 \mathrm{~min}$ run), purity $81.5 \%$. HRMS (ESI) $m / z$ : calculated for $\mathrm{C}_{48} \mathrm{H}_{51} \mathrm{BF}_{2} \mathrm{~N}_{8} \mathrm{O}_{4} \mathrm{~S}[\mathrm{M}+2 \mathrm{H}]^{2+}$ 442.1902; found 442.1881. Calculated for $\mathrm{C}_{48} \mathrm{H}_{50} \mathrm{BF}_{2} \mathrm{~N}_{8} \mathrm{O}_{4} \mathrm{~S}[\mathrm{M}+\mathrm{H}]^{+}$883.3731; found 883.3779.

\subsection{Plasmids}

The cDNA encoding the rat $\mathrm{mGlu}_{5 \mathrm{~b}} \mathrm{R}$ [25] was amplified by PCR using the following primers: FmGlu5NL (5'-AAACAGAATTCAGTGAGAGGAGGGTGGTGGCTC-3') and RmGlu5NL (5'-AAAGATCTAGATCACAACGATGAAGAACTCTGCG-3') and cloned into the EcoRI/XbaI sites of pNLF1-secN [CMV/Hygro] vector (Promega, Stockholm, Sweden), encoding a fusion of the secretory signal peptide sequence of IL- 6 on the $\mathrm{N}$ terminus of NanoLuc (Nluc). The $\mathrm{mGlu}_{5 \mathrm{~b}} \mathrm{R}^{\mathrm{NL}}$ construct was confirmed by sequencing analysis. The resulting open reading frame therefore encoded a fusion of secreted Nluc at the $\mathrm{N}$ terminus of $\mathrm{mGlu}_{5 \mathrm{~b}} \mathrm{R}$. The $\mathrm{mGlu}_{5 b} \mathrm{R}^{\mathrm{SNAP}}$ construct was previously described [26]. 


\subsection{Cell Culture and Transfection}

Human embryonic kidney (HEK)-293T cells were grown in Dulbecco's modified Eagle's medium (DMEM) (Sigma-Aldrich, St. Louis, MO, USA) supplemented with $1 \mathrm{mM}$ sodium pyruvate, $2 \mathrm{mM}$ L-glutamine, $100 \mathrm{U} / \mathrm{mL}$ streptomycin, $100 \mathrm{mg} / \mathrm{mL}$ penicillin and $5 \%(v / v)$ fetal bovine serum at $37^{\circ} \mathrm{C}$ and in an atmosphere of $5 \% \mathrm{CO}_{2}$. HEK-293T cells growing in $60 \mathrm{~cm}^{2}$ plates were transfected with the cDNA encoding the different plasmids using linear PolyEthylenImine reagent (PEI) (Polysciences Inc., Valley Road Warrington, PA, USA) as previously described [27].

\subsection{Membrane Preparations and Immunoblotting}

To prepare membranes, cells were homogenized in ice-cold $50 \mathrm{mM}$ Tris- $\mathrm{HCl}$ (pH 7.4), 1 mM EDTA, $300 \mathrm{mM} \mathrm{KCl}$ buffer containing a protease inhibitor cocktail (Roche Molecular Systems, Pleasanton, CA, USA) using a Polytron for three periods of $10 \mathrm{~s}$ each. The homogenate was centrifuged for 10 $\min$ at $1000 \times \mathrm{g}$ at $4{ }^{\circ} \mathrm{C}$. The resulting supernatant was centrifuged for $30 \mathrm{~min}$ at $12,000 \times \mathrm{g}$ at $4{ }^{\circ} \mathrm{C}$. Membranes were dispersed in $50 \mathrm{mM}$ Tris $\mathrm{HCl}$ (pH 7.4) and $10 \mathrm{mM} \mathrm{MgCl}_{2}$ and protein concentration determined using the BCA protein assay kit (Thermo Fisher Scientific, Inc., Rockford, IL, USA). Sodium dodecyl sulfate-polyacrylamide gel electrophoresis (SDS/PAGE) was performed using 10\% polyacrylamide gels. Proteins were transferred to Hybond ${ }^{\circledR}$-LFP polyvinylidene difluoride (PVDF) membranes (GE Healthcare, Chicago, IL, USA) using a Trans-Blot ${ }^{\circledR}$ SD Semi-Dry Transfer Cell (Bio-Rad, Hercules, CA, USA). PVDF membranes were blocked with 5\% (wt/vol) dry non-fat milk in PBS containing $0.05 \%$ Tween-20 (PBS-T) during $2 \mathrm{~h}$ and immunoblotted using rabbit anti-mGlu $\mathrm{R}$ antibody $\left(1 \mu \mathrm{g} / \mathrm{mL}\right.$; Millipore, Billerica, MA, USA) in blocking solution overnight at $4{ }^{\circ} \mathrm{C}$. PVDF membranes were washed with PBS-T three times ( 5 min each) before incubation with a horseradish peroxidase (HRP)-conjugated goat anti-rabbit IgG (1/30,000; Pierce Biotechnology, Rockford, IL, USA) in blocking solution at $20^{\circ} \mathrm{C}$ during $2 \mathrm{~h}$. After washing the PVDF membranes with PBS-T three times (5 min each) the immunoreactive bands were developed using a chemiluminescent detection kit (Thermo Fisher Scientific) and detected with an Amersham Imager 600 (GE Healthcare).

\subsection{NanoBRET Experiments}

The NanoBRET assay was performed on cells transiently transfected with $\mathrm{mGlu}_{5} \mathrm{R}^{\mathrm{NL}}$, according to [17]. In brief, cells were re-suspended in Hank's Balanced Salt Solution (HBSS; $137 \mathrm{mM}$ $\mathrm{NaCl}, 5.4 \mathrm{mM} \mathrm{KCl}, 0.25 \mathrm{mM} \mathrm{Na} 2 \mathrm{HPO} 4,0.44 \mathrm{mM}$ KH2PO4, $1.3 \mathrm{mM} \mathrm{CaCl} 2,1.0 \mathrm{mM} \mathrm{MgSO} 4,4.2 \mathrm{mM}$ $\mathrm{NaHCO}$, pH 7.4), containing $10 \mathrm{mM}$ glucose, and seeded into poli-ornitine coated white 96-well plates. After $24 \mathrm{~h}$, cells were challenged with/without the non-labelled mGlu ${ }_{5} \mathrm{R}$ NAM (MTEP; Tocris Bioscience; Ellisville, MI, USA) and incubated for $1 \mathrm{~h}$ at $37^{\circ} \mathrm{C}$. Subsequently, the fluorescent ligand was added and the plate returned to $37^{\circ} \mathrm{C}$ for $1 \mathrm{~h}$. Finally, coelenterazine 400a (NanoLight Technologies; Pinetop, AZ, USA) was added at a final concentration of $1 \mu \mathrm{M}$, and readings were performed after 5 min using a CLARIOStar plate reader (BMG Labtech; Durham, NC, USA). The donor and acceptor emission was measured at $490 \pm 10 \mathrm{~nm}$ and $650 \pm 40 \mathrm{~nm}$, respectively. The raw NanoBRET ratio was calculated by dividing the $650 \mathrm{~nm}$ emission by the $490 \mathrm{~nm}$ emission and the values fitted by non-linear regression using GraphPad Prism 7 (GraphPad Software, La Jolla, CA, USA). In competition studies, results were expressed as a percentage of the maximum signal obtained (mBU; miliBRET Units).

\subsection{Intracellular Calcium Determinations}

The mGlu $_{5} \mathrm{R}$-mediated intracellular $\mathrm{Ca}^{2+}$ accumulation was assessed by means of a luciferase reporter assay based in the expression of the nuclear factor of activated T-cells (NFAT), as previously described [28]. In brief, cells were transfected with the cDNA encoding the mGlu $\mathrm{R}^{\mathrm{SNAP}}$ and the NFAT-luciferase reporter (pGL4-NFAT-RE/luc2p; Promega). Plasmids were co-transfected by preparing a $1: 1$ solution $(1.5+1.5 \mu \mathrm{g})$ in $\mathrm{NaCl}$ and mixing it with a solution containing $14.5 \mu \mathrm{g}$ of PEI. The final solution was added to the cells plate for $4 \mathrm{~h}$ and thereafter replaced with fresh 
medium. After $36 \mathrm{~h}$ post-transfection, cells were first labelled with a non-permeable SNAP substrate (SNAP-Surface 647 ligand; New England BioLabs, Ipswich, MA, USA), as previously described [29]. Thereafter, cells were incubated with quisqualic acid in the presence/absence of the different NAMs tested for $6 \mathrm{~h}$. Subsequently, cells were harvested with passive lysis buffer (Promega) and transferred to 96-wells white plates. First, fluorescence was assessed and thereafter the luciferase activity of cell extracts was determined using a luciferase Bright-GloTM assay (Promega) according to the manufacturer's protocol. Both fluorescence $(647 \mathrm{~nm})$ and luciferase activity $(535 \mathrm{~nm})$ were determined in a CLARIOStar Optima plate-reader (BMG Labtech). The ratio between 535/647 nm was calculated.

\subsection{Imaging}

The localization of the mGlu 5 R NAMs was evaluated using a live-cell laser scanning confocal microscopy. To this end, cells were transfected with $\mathrm{mGlu}_{5 \mathrm{~b}} \mathrm{R}^{\mathrm{SNAP}}$ and, upon $36 \mathrm{~h}$ post-transfection, seeded into a chamber culture slide (Thermo Fisher Scientific). After $24 \mathrm{~h}$, the medium was replaced by HBSS and single cells were examined using a Carl Zeiss LSM 880 spectral confocal laser scanning microscope (Carl Zeiss Microscopy GmbH, Jena, Germany) equipped with a multiline argon laser ( $458 \mathrm{~nm}, 488 \mathrm{~nm}$ and $514 \mathrm{~nm}$ ), 405nm and $561 \mathrm{~nm}$ diode lasers and $633 \mathrm{~nm} \mathrm{He} / \mathrm{Ne}$ laser (Centres Científics i Tecnològics, Universitat de Barcelona, Bellvitge Campus, Barcelona, Spain) using a $63 \times$ oil immersion objective (1.4 numerical aperture) an image resolution of $1024 \times 1024$ pixels. To assess association and diffusion of the fluorescent NAM $(4 \mathbf{a})$, it was added $(5 \mu \mathrm{M})$ to the chamber and live-cell imaging was performed for $5 \mathrm{~min}$.

\subsection{Statistics}

The number of samples (n) in each experimental condition is indicated in figure legends. Statistical analysis and significance is indicated for each experiment.

\section{Conclusions}

In summary, we have developed a new series of fluorescent ligands acting as NAMs for the mGlu ${ }_{5} \mathrm{R}$. Interestingly, we showed that these ligands bind and modulate the receptor's activity. In addition, as these they are compatible with NanoBRET binding experiments, they may eventually evolve into a useful tool for the pharmacological study of mGlu5R both in vitro and in vivo.

Author Contributions: V.F.-D. performed experiments, analyzed results and wrote the paper. M.Q. synthesized the fluorescent ligands. J.A. and C.A. performed experiments and analyzed results. M.D.P.R. synthesized the BODIPY dye reagents. S.V.C. and F.C. conceived the project, analyzed results and wrote the paper. All authors have read and agreed to the published version of the manuscript.

Funding: This work was supported by FEDER/Ministerio de Ciencia, Innovación y Universidades-Agencia Estatal de Investigación (SAF2017-87349-R) and ISCIII (PIE14/00034), the Catalan government (2017 SGR 1604), Fundació la Marató de TV3 (Grant 20152031), FWO (SBO-140028) to FC. We thank Centres de Recerca de Catalunya (CERCA) Programme/Generalitat de Catalunya for IDIBELL institutional support.

Acknowledgments: We thank Esther Castaño and Benjamín Torrejón, from the CCiT-Bellvitge Campus of the University of Barcelona, for the technical assistance.

Conflicts of Interest: The authors declare no conflict of interest. The funders had no role in the design of the study; in the collection, analyses, or interpretation of data; in the writing of the manuscript; or in the decision to publish the results.

\section{References}

1. Marinissen, M.J.; Gutkind, J.S. G-protein-coupled receptors and signaling networks: Emerging paradigms. Trends Pharmacol. Sci. 2001, 22, 368-376. [CrossRef]

2. Wold, E.A.; Chen, J.; Cunningham, K.A.; Zhou, J. Allosteric modulation of class A GPCRs: Targets, agents, and emerging concepts. J. Med. Chem. 2019, 62, 88-127. [CrossRef] [PubMed] 
3. Sheffler, D.J.; Gregory, K.J.; Rook, J.M.; Conn, P.J. Allosteric modulation of metabotropic glutamate receptors. Adv. Pharmacol. 2011, 62, 37-77. [PubMed]

4. Melancon, B.J.; Hopkins, C.R.; Wood, M.R.; Emmitte, K.A.; Niswender, C.M.; Christopoulos, A.; Conn, P.J.; Lindsley, C.W. Allosteric modulation of seven transmembrane spanning receptors: Theory, practice, and opportunities for central nervous system drug discovery. J. Med. Chem. 2012, 55, 1445-1464. [CrossRef]

5. Gregory, K.J.; Dong, E.N.; Meiler, J.; Conn, P.J. Allosteric modulation of metabotropic glutamate receptors: Structural insights and therapeutic potential. Neuropharmacology 2011, 60, 66-81. [CrossRef]

6. Möhler, H.; Fritschy, J.M.; Rudolph, U. A new benzodiazepine pharmacology. J. Pharmacol. Exp. Ther. 2002, 300, 2-8. [CrossRef] [PubMed]

7. Gentry, P.R.; Sexton, P.M.; Christopoulos, A. Novel allosteric modulators of G protein-coupled receptors. J. Biol. Chem. 2015, 290, 19478-19488. [CrossRef]

8. Thal, D.M.; Glukhova, A.; Sexton, P.M.; Christopoulos, A. Structural insights into G-protein-coupled receptor allostery. Nature 2018, 559, 45-53. [CrossRef] [PubMed]

9. Gether, U.; Lin, S.; Ghanouni, P.; Ballesteros, J.A.; Weinstein, H.; Kobilka, B.K. Agonists induce conformational changes in transmembrane domains III and VI of the beta2 adrenoceptor. Embo J. 1997, 16, 6737-6747. [CrossRef]

10. Changeux, J.P.; Christopoulos, A. Allosteric modulation as a unifying mechanism for receptor function and regulation. Cell 2016, 166, 1084-1102. [CrossRef]

11. Conn, P.J.; Christopoulos, A.; Lindsley, C.W. Allosteric modulators of GPCRs: A novel approach for the treatment of CNS disorders. Nat. Rev. Drug Discov. 2009, 8, 41-54. [CrossRef] [PubMed]

12. Lindsley, C.W.; Emmitte, K.A.; Hopkins, C.R.; Bridges, T.M.; Gregory, K.J.; Niswender, C.M.; Conn, P.J. Practical strategies and concepts in GPCR allosteric modulator discovery: Recent advances with metabotropic glutamate receptors. Chem. Rev. 2016, 116, 6707-6741. [CrossRef] [PubMed]

13. Kew, J.N.C. Positive and negative allosteric modulation of metabotropic glutamate receptors: Emerging therapeutic potential. Pharmacol. Ther. 2004, 104, 233-244. [CrossRef] [PubMed]

14. Niswender, C.M.; Conn, P.J. Metabotropic glutamate receptors: Physiology, pharmacology, and disease. Annu. Rev. Pharmacol. Toxicol. 2010, 50, 295-322. [CrossRef] [PubMed]

15. Pin, J.P.; Duvoisin, R. The metabotropic glutamate receptors: Structure and functions. Neuropharmacology 1995, 34, 1-26. [CrossRef]

16. Cottet, M.; Faklaris, O.; Falco, A.; Trinquet, E.; Pin, J.P.; Mouillac, B.; Durroux, T. Fluorescent ligands to investigate GPCR binding properties and oligomerization. Biochem. Soc. Trans. 2013, 41, 148-153. [CrossRef]

17. Stoddart, L.A.; Johnstone, E.K.M.; Wheal, A.J.; Goulding, J.; Robers, M.B.; Machleidt, T.; Wood, K.V.; Hill, S.J.; Pfleger, K.D.G. Application of BRET to monitor ligand binding to GPCRs. Nat. Methods 2015, 12, 661-663. [CrossRef]

18. Verdoes, M.; Hillaert, U.; Florea, B.I.; Sae-Heng, M.; Risseeuw, M.D.P.; Filippov, D.V.; van der Marel, G.A.; Overkleeft, H.S. Acetylene functionalized BODIPY dyes and their application in the synthesis of activity based proteasome probes. Bioorganic Med. Chem. Lett. 2007, 17, 6169-6171. [CrossRef]

19. Qian, M.; Wouters, E.; Dalton, J.A.R.; Risseeuw, M.D.P.; Crans, R.A.J.; Stove, C.; Giraldo, J.; Van Craenenbroeck, K.; Van Calenbergh, S. Synthesis toward Bivalent Ligands for the Dopamine D2 and Metabotropic Glutamate 5 Receptors. J. Med. Chem. 2018, 61, 8212-8225. [CrossRef]

20. Servier Medical Art. Available online: https://smart.servier.com/image-set-download/ (accessed on 13 March 2020).

21. Youssef, E.A.; Berry-Kravis, E.; Czech, C.; Hagerman, R.J.; Hessl, D.; Wong, C.Y.; Rabbia, M.; Deptula, D.; John, A.; Kinch, R.; et al. Effect of the mGluR5-NAM basimglurant on behavior in adolescents and adults with fragile $X$ syndrome in a randomized, double-blind, placebo-controlled trial: FragXis phase 2 results. Neuropsychopharmacology 2018, 43, 503-512. [CrossRef]

22. Barnes, S.A.; Sheffler, D.J.; Semenova, S.; Cosford, N.D.P.; Bespalov, A. Metabotropic glutamate receptor 5 as a target for the treatment of depression and smoking: Robust preclinical data but inconclusive clinical efficacy. Biol. Psychiatry 2018, 83, 955-962. [CrossRef] [PubMed]

23. Zwier, J.M.; Roux, T.; Cottet, M.; Durroux, T.; Douzon, S.; Bdioui, S.; Gregor, N.; Bourrier, E.; Oueslati, N.; Nicolas, L.; et al. A fluorescent ligand-binding alternative using Tag-lite(R) technology. J. Biomol. Screen. 2010, 15, 1248-1259. [CrossRef] [PubMed] 
24. Machleidt, T.; Woodroofe, C.C.; Schwinn, M.K.; Méndez, J.; Robers, M.B.; Zimmerman, K.; Otto, P.; Daniels, D.L.; Kirkland, T.A.; Wood, K.V. NanoBRET-A novel BRET platform for the analysis of protein-protein interactions. ACS Chem. Biol. 2015, 10, 1797-1804. [CrossRef] [PubMed]

25. Cabello, N.; Gandia, J.; Bertarelli, D.C.; Watanabe, M.; Lluis, C.; Franco, R.; Ferre, S.; Lujan, R.; Ciruela, F. Metabotropic glutamate type 5 , dopamine $\mathrm{D}(2)$ and adenosine $\mathrm{A}(2 \mathrm{a})$ receptors form higher-order oligomers in living cells. J. Neurochem. 2009, 109, 1497-1507. [CrossRef]

26. Morató, X.; Luján, R.; Gonçalves, N.; Watanabe, M.; Altafaj, X.; Carvalho, A.L.; Fernández-Dueñas, V.; Cunha, R.A.; Ciruela, F. Metabotropic glutamate type 5 receptor requires contactin-associated protein 1 to control memory formation. Hum. Mol. Genet. 2018, 27, 3528-3541. [CrossRef]

27. Longo, P.A.; Kavran, J.M.; Kim, M.-S.; Leahy, D.J. Transient mammalian cell transfection with polyethylenimine (PEI). Methods Enzymol. 2013, 529, 227-240.

28. Borroto-Escuela, D.O.; Romero-Fernandez, W.; Tarakanov, A.O.; Ciruela, F.; Agnati, L.F.; Fuxe, K. On the existence of a possible A2A-D2-beta-Arrestin2 complex: A2A agonist modulation of D2 agonist-induced beta-arrestin2 recruitment. J. Mol. Biol. 2011, 406, 687-699. [CrossRef]

29. Fernández-Dueñas, V.; Gómez-Soler, M.; Jacobson, K.A.; Kumar, S.T.; Fuxe, K.; Borroto-Escuela, D.O.; Ciruela, F. Molecular determinants of $\mathrm{A}_{2 \mathrm{~A}} \mathrm{R}-\mathrm{D}_{2} \mathrm{R}$ allosterism: Role of the intracellular loop 3 of the $\mathrm{D}_{2} \mathrm{R}$. J. Neurochem. 2012, 123, 373-384. [CrossRef]

Sample Availability: Samples of the compounds $\mathbf{4 a - 4 f}$ are available from the authors. 